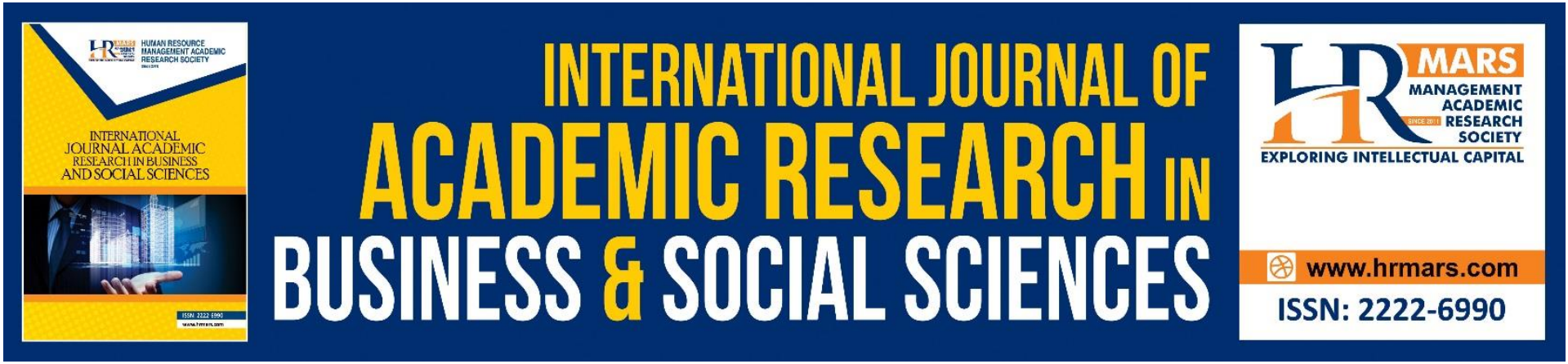

\title{
A Taxonomical Study of Tourism Experience Based on Bibliometric Analysis
}

\section{Liew Jan-Fui, Zuraidah Sulaiman}

To Link this Article: http://dx.doi.org/10.6007/IJARBSS/v12-i1/11594

DOI:10.6007/IJARBSS/v12-i1/11594

Received: 17 November 2021, Revised: 21 December 2021, Accepted: 08 January 2022

Published Online: 23 January 2022

In-Text Citation: (Jan-Fui \& Sulaiman, 2022)

To Cite this Article: Jan-Fui, L., \& Sulaiman, Z. (2022). A Taxonomical Study of Tourism Experience Based on Bibliometric Analysis. International Journal of Academic Research in Business and Social Sciences, 12(1), 1121-1142.

\section{Copyright: (c) 2022 The Author(s)}

Published by Human Resource Management Academic Research Society (www.hrmars.com)

This article is published under the Creative Commons Attribution (CC BY 4.0) license. Anyone may reproduce, distribute, translate and create derivative works of this article (for both commercial and non0-commercial purposes), subject to full attribution to the original publication and authors. The full terms of this license may be seen at: http://creativecommons.org/licences/by/4.0/legalcode

Vol. 12, No. 1, 2022, Pg. $1121-1142$

Full Terms \& Conditions of access and use can be found at http://hrmars.com/index.php/pages/detail/publication-ethics 


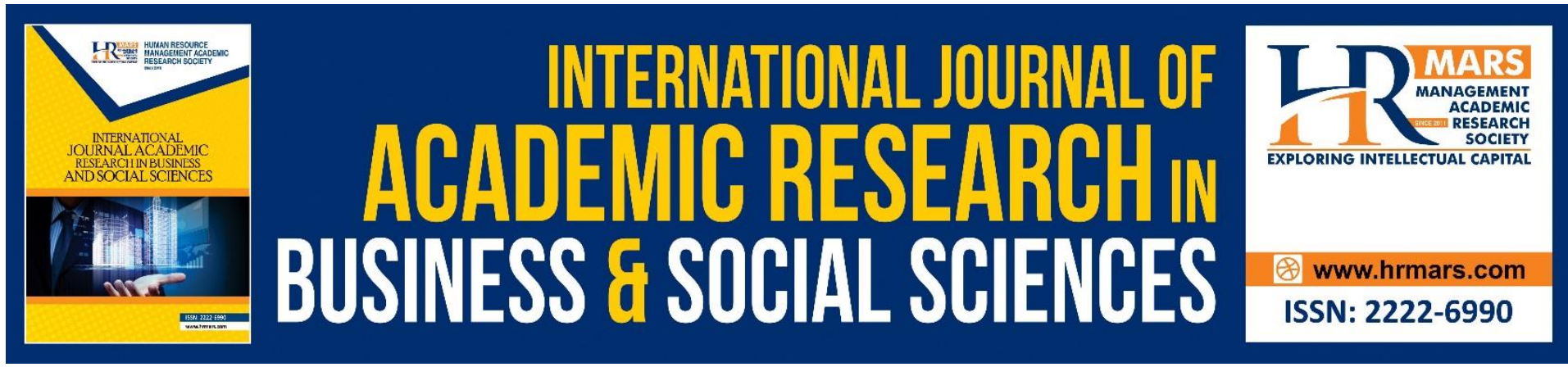

\title{
A Taxonomical Study of Tourism Experience Based on Bibliometric Analysis
}

\author{
Liew Jan-Fui, Zuraidah Sulaiman \\ Department of Business Administration, Azman Hashim International Business School, \\ Universiti Teknologi Malaysia, 81300 Skudai Johor, Malaysia \\ Email: jfliew2@graduate.utm.my, zuraidahm@utm.my
}

\begin{abstract}
Tourism is creating and delivering travel and visiting experiences. The 'experience economy concept' introduction highlights the managerial focus is shifting from delivering 'tourism products' to providing 'tourism experiences' (TE). This study reviews the trends in the field of TE. A bibliometric analysis method in this study was carried out based on publications retrieved from the Scopus database using the VOSViewer software tool. This article analysed 2,638 articles published from 1966 to 2019 on TE. The results showed that since 2009, the number of publications had increased annually and resulted in overall accumulated publications. This study had employed co-authorship among authors and affiliated countries and the co-occurrence of author keywords. Conclusively, $56 \%$ of the existing literature on TE produce in Australia, the USA, China, and the UK. However, due to the multidisciplinary complexity noted within this tourism industry, various scientific journals contain articles on TE. Among the most productive tourism experience research universities of 15 leading countries, seven were the world's top 50 universities for Hospitality and Leisure Management academy. The network visualisation map illustrated that 'experience', 'authenticity', 'satisfaction', and 'motivation' emerged as the most encountered terms in the TE research domain. This review concluded with theoretical and practical implications of the study and the directions for future research.
\end{abstract}

Keywords: Tourism Experience, Tourism, Bibliometric Analysis, VOSViewer, Review

\section{Introduction}

Tourism experiences (TE) come together in an expected experience that influences the perception of the experience. Otto and Ritchie (1996) pointed out that experience is the psychological state of tourists during service encounters that reflect in their evaluation of service providers. Tourists build their own experiences based on their interests. Their social and cultural backgrounds and the different experiences of each tourist depend on their participation and experience. Pine and Gilmore (1998) asserted that experience is a complex phenomenon that many perspectives should explore using a holistic approach.

Tourist destinations need to be competitive and expect long-term success, understanding tourists' needs, desires, and expectations are essential. The TE is 
multidimensional. Various involvements, including before, during, and after the trip, will affect the overall TE of tourists (Buhalis and Amaranggana, 2014). Pine and Gilmore (1998) identified five core elements critical for creating authentic experiences: 1 ) experience theme; 2) use positive signals; 3) remove negative communication; 4) mix in memorabilia; and 5) use all senses. Thus, identifying how tourists build and recollect their memories is essential for any destination manager. Researchers have shown the consequences of positive experiences remembered; it encourages tourists to repeat an event, satisfaction, and positive word-ofmouth (Manthiou et al., 2016).

This study deployed the bibliometric analysis based on the literature recorded in the Scopus citation database. Bibliometric analysis is the utilisation of statistical methods to analyse quantitative data about scientific publications. The Scopus database is the primary data source. Other scholarly databases, such as Web of Science (WoS), can overlap during the indexing process of the journal (Veira and Gomez, 2009). According to Sánchez, Del Río, and García (2017), the annual distribution of the integrated articles shows a clear link between the WoS and Scopus. However, Scopus has faster growth and secure records. Hence, using the Scopus database is an attempt to cover subjects excluded from WoS or other databases. The search is limited to the Scopus database - the largest abstract and citation database of peer-reviewed literature in science, technology, medicine, social sciences, and arts and humanities domains.

To the best of our knowledge, there was no bibliometric study on TE. Bibliometric research allows a comparative review of scientific articles and their accompanying citation counts (de Bellis, 2009) to identify the themes and trends of the journals. This study assessed TE publication using the bibliometric analysis to achieve the following objectives:

(i) to examine the trend of TE publication

(ii) to show contributions of prolific authors, the most productive academic institutions, and leading countries in publications; and

(iii) to highlight the main terminology and research topics.

This article can facilitate academic researchers and industry practitioners to better understand the TE research patterns besides exploring the possibilities and opportunities for future research.

\section{Methodology Approach}

Bibliometric analysis is a systematic approach to understand global research trends in a specific area. It is an analysis based on academic literature database outputs. This approach distinguishes a bibliometric research paper from a review paper intended to address a particular topic, latest developments, issues, and potential directions. The bibliometric approach provides research newcomers who may struggle to understand the tourism sector with insights into influential authors and works (Benckendorff and Zehrer, 2013). In this study, the bibliometric analysis was executed by adhering to the search strategies employed in the literature (Md Khudzari, 2018). This study employed bibliometric analysis to assess articles and papers retrieved from the Scopus database. The database belongs to the Elsevier editorial group that provides a general view of scientific publications. 
Data Sources and Search Technique

The data and information were obtained via a database search of articles related to TE on 23 and 28 February 2020. The search theme applied was research articles containing 'tourism experience' or 'travel experience' or 'tourist experience' keywords on the title and abstract. The search result shows that the oldest publication dates back to an article published by Arnold $\mathrm{H}$ in 1966.

First, the query string used for search is TITLE-ABS ('tourism experience' OR 'travel experience' OR 'tourist experience') AND (LIMIT-TO (SRCTYPE, ' $j$ ') OR LIMIT-TO (SRCTYPE, ' $p$ ')) AND (LIMIT-TO (DOCTYPE, 'ar') OR LIMIT-TO (DOCTYPE, 'cp')) AND (EXCLUDE (PUBYEAR, 2020)). This query string resulted in 2,818 documents. Then, additional phrases were added to the query string to exclude review articles in the analysis. As a result, 413 articles were irrelevant to this study. Of this, this study removed180 articles after reviewing the abstracts and full texts in the articles. Such articles contained several terms, such as review, recent, progress, critical, revisit, advance, and highlight in both title and abstract. The review articles were identified using Scopus unique article identifier-EID. The review articles did not appear in the following search results. Lastly, this study considers 2,638 documents for further analysis.

One best way to obtain the most accurate authors' information is through author identification (ID) from the Scopus domain code (AU-ID). An author profile collects information in one profile, such as the author's name, ID, affiliation, number of publications, total citations, and authors' $h$-index. All the information is vital to conduct a scientific publication analysis. Similarly, using a domain code AFFILCOUNTRY, the single-country publication (SCP) information extract limits the search result to a specific country. The researcher searched the literature and validated the results based on year, source, author, affiliation, country, subject area, keywords, and document type.

This study used bibliometric metrics for ranking purposes, such as the total publications, citations, CiteScore, and h-index. Figure 1 shows the data collection process. Further information on the search strategies, view Table S1, Supplementary Material.

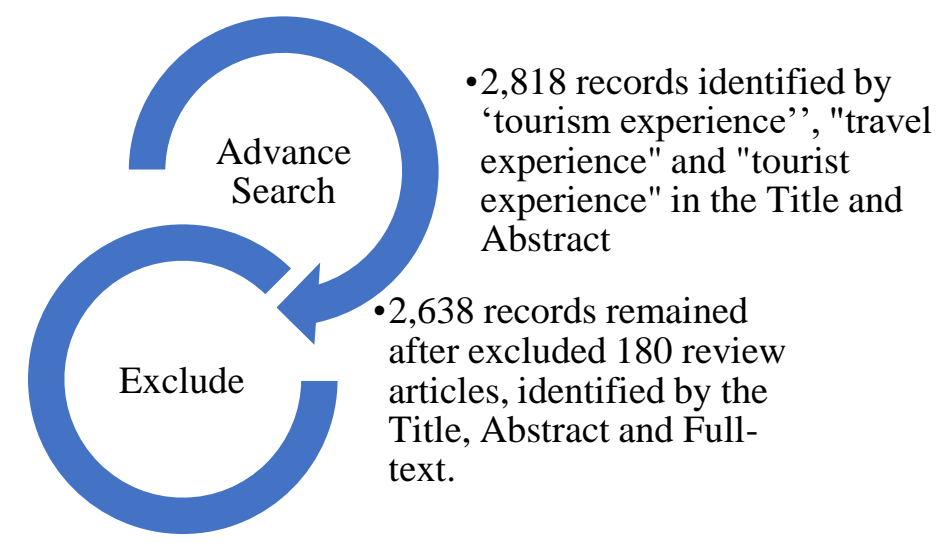

Figure 1. Data Collection Process 
Bibliometric Map

Visualisation of Similarities (VOS) Viewer is a software tool for creating maps based on network data. The software presents mapping data using co-citation and keyword cooccurrence techniques (Van Eck and Waltman, 2020). It translates and exports data into various formats, such as reusable Pajek files. This study exported 2,638 articles, author keywords, bibliographical, and citation information to VOSviewer.

Bibliometric mapping created using VOSviewer contains analysis items, including objects of interest (countries and author keywords). Two items that appear in bibliometric mapping have a link or connection, or relationship. The link represents a positive numerical value with strength - a higher value denotes a more significant link. The co-authorship analysis shows the link strength between countries indicates the number of publications that two affiliated countries have co-authored. In contrast, the total link strength indicates the total strength of the co-authorship links of a given country with other countries. Likewise, for cooccurrence analysis, author keyword link strength indicates the number of publications in which two keywords appear simultaneously.

\section{Co-authorship Analysis}

Co-authorship is used to measure scientific (or research) collaboration in scholarly publications. In this study, co-authorship analysis included 115 countries affiliated with 343 authors. The affiliated countries are clustered into five continents: Cluster 1-Asia, Cluster 2Europe, Cluster 3-America, Cluster 4-Africa, and Cluster 5-Oceania.

\section{Co-occurrence Analysis}

Co-occurrence analysis of author keywords (not an indexed Scopus keyword) included 6,714 keywords from 2,638 articles. Upon importing the list of author keywords to VOSviewer, the researcher analysed the single synonymous terms and congeneric phrases. For example, for terms 'behavioural intention' and 'behavioural intentions', the latter is denoted as a single aspect and reassigned as 'behavioural intention'. Subsequently, overlay visualisation mode shows the average year of publication, occurrences, and keywords link strength. Keyword colour represents the average year a keyword appears in released documents; lighter colour reflects recent publications.

\section{Results and Discussion}

\section{Publication Output and Research Interest Trend}

Overall, the number of publications increased throughout the studies. Figure 2 shows the annual and cumulative publications from 1966 to 2019. In total, there were 2,818 TE researchrelated articles found in the Scopus database. The year 2020 was omitted from this analysis as it is still in progress. The earliest recorded publication was in 1966. The Scopus annual number of publications has grown exponentially, particularly after 2000, indicating that the research has garnered attention. Besides, the figure displays that before 2001, minimal researchers paid attention to TE research. A substantial positive jump from one year to another was noted from 2016 to 2017, with a difference of 44 publications. The highest drop was between 2001 and 2002, which involved a difference of 15 items. 


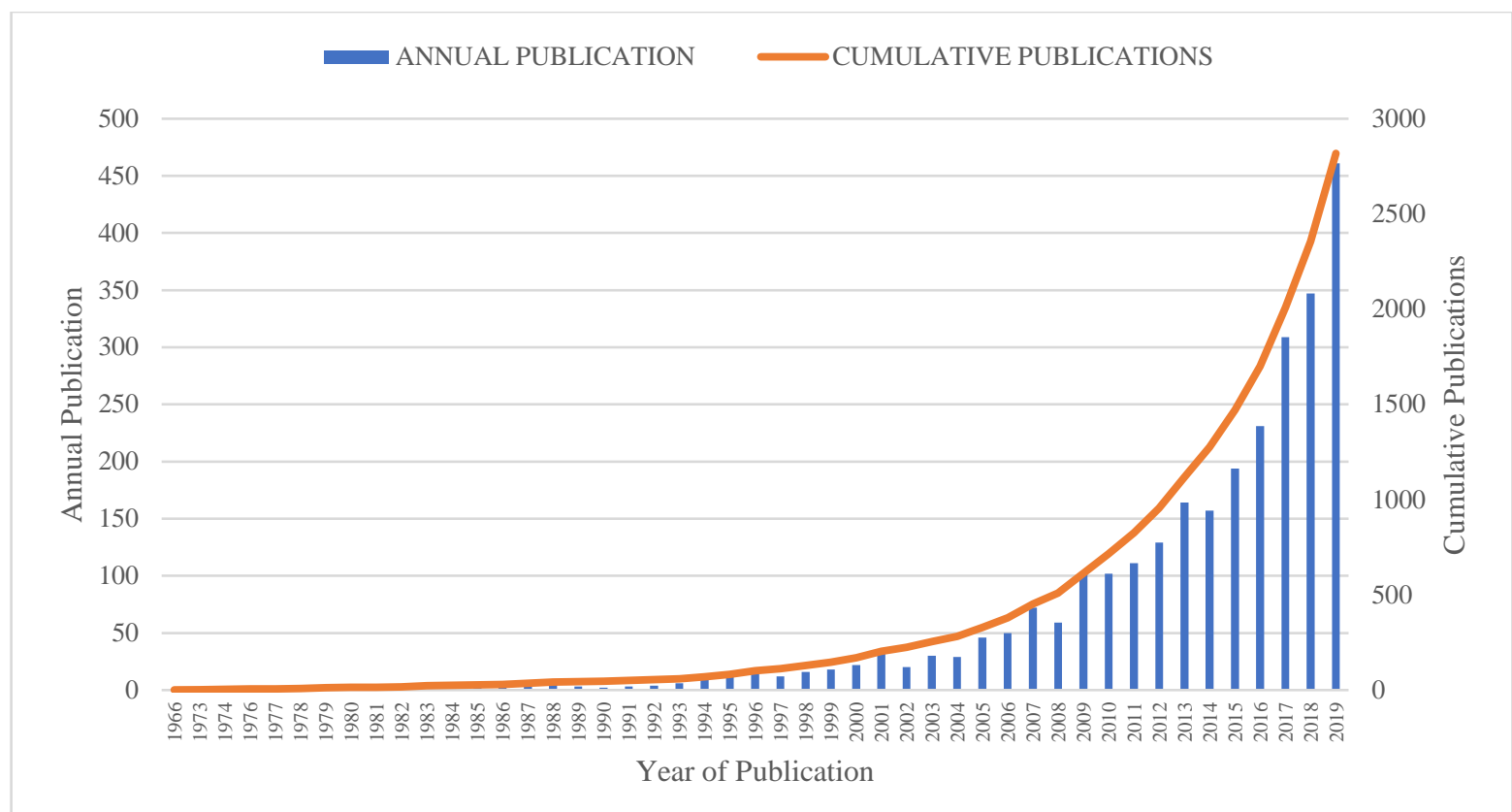

Figure 1. The annual and cumulative research articles on tourism experience indexed in Scopus from 1966 to 2019

The average number of articles published every year was 52.19 . Nevertheless, $10 \%$ of the complete documents are available for free. The reader must pay to view the remainder of the documents to access the information found within. According to Wagner (2010), articles published in open-access journals get more cite than other articles. This notion is in line with a recent study that open access PhD theses increased visibility and use, besides producing a significant citation rate (Ferreras-Fernández, García-Peñalvo, Merlo-Vega and Martín-Rodero, 2016). Consequently, this study suggested classified articles as open access journals to enhance article visibility and total citations.

As shown in Figure 2, most of the TE research work appears after 2006. There were 2,489 publications between 2006 and 2019, representing $88.3 \%$ of the total publications, with 2019 recording the most publications (461 or $16.4 \%$ of the total publications). Thus, the focus of TE was in a multidisciplinary area. The total publications can clarify this for each of the following subject areas (see Figure 3): Business, Management and Accounting $(1,725)$ followed by Social Science $(1,552)$, Environment Science (356), Computer Science (331), Engineering (254), Art and Humanities (200), as well as Earth and Planetary Sciences (102). 


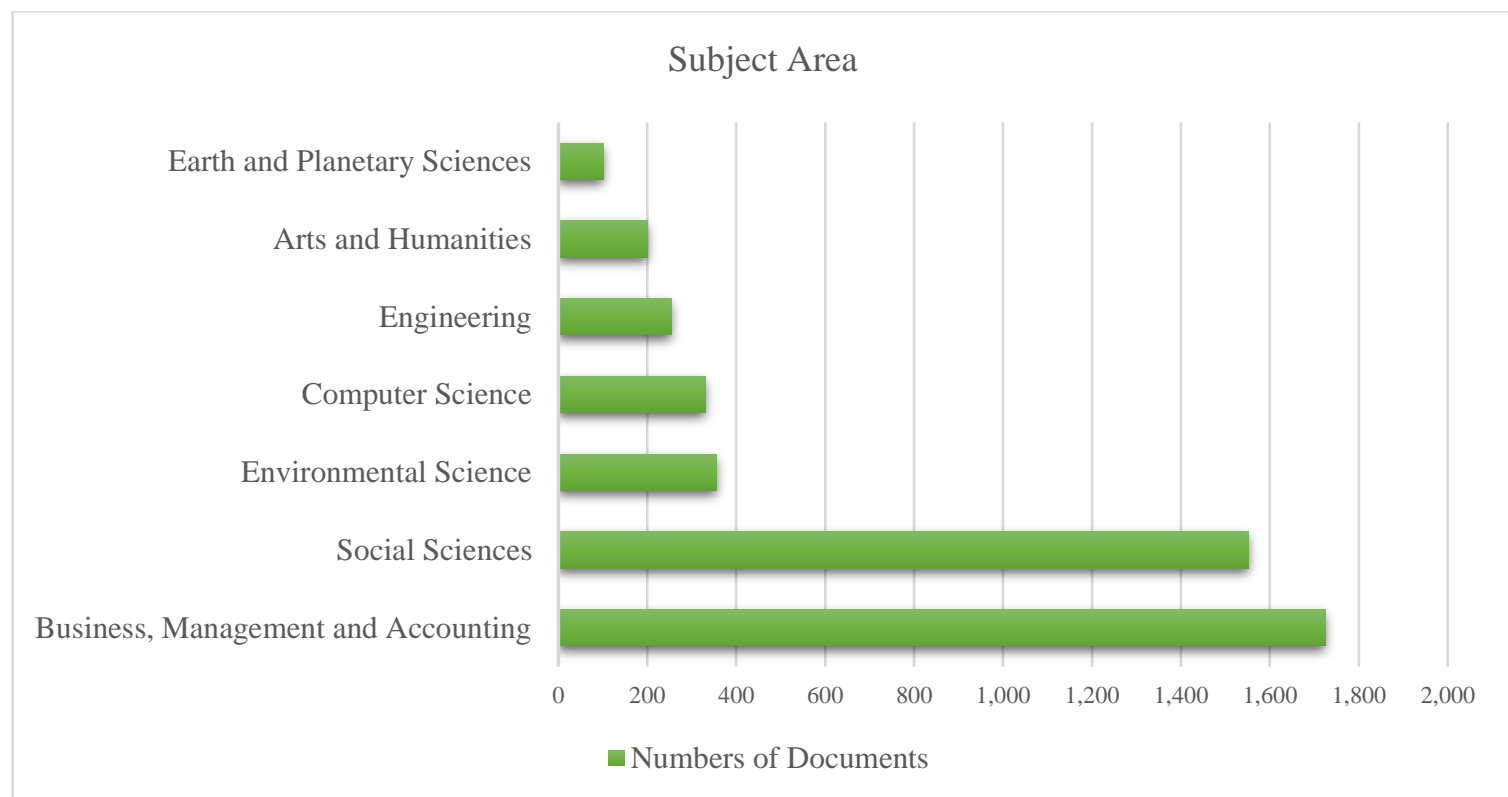

Figure 2. Distribution of documents according to a subject area

Top Preferred Journal

The results showed that six different publishers own the top 10 most productive journals (see Table 1). Elsevier had published the top two articles, followed by SAGE in the third. Meanwhile, Taylor \& Francis held most of the top 10 articles from fourth to seventh place. Another three articles were published by Wiley-Blackwell, Multidisciplinary Digital Publishing Institute (MDPI), and Cognizant Communication Corporation. The most productive journal was Tourism Management with 125 articles (4.7\%) of the total publications, followed by Annals of Tourism Research (117, 4.4\%), Journal of Travel Research (96, 3.6\%), as well as Journal of Travel and Tourism (65, 2.5\%). An Elsevier tourism journal, Annals of Tourism Research, had received the highest citations; 9,827. One of the publications in 1999 was the most cited article, with 1,336 citations. These publications by Ning Wang, titled 'Rethinking authenticity in tourism experience', were conceptual clarification of the meaning of authenticity in the tourism experience.

CiteScore metric launched by Elsevier is a set of citation-based metrics for the journal. CiteScore Tracker provides an updated view of a journal achievement throughout the year (Zijlstra and McCullough, 2016). According to the CiteScore 2018 report, two journals in the TE study had achieved above 5 CiteScore. Journals of the highest and lowest CiteScore belonged to Tourism Management (8.2) and Tourism Analysis (1.22), respectively. While Tourism Management ranked first, the total citations were significantly lower than the Annals of Tourism Research that ranked the second-highest journal with 9,827 citations. The cause of lower total citation is ascribed to article accessibility. Therefore, CiteScore should never be considered as the main reason for articles submission. Instead, the author should consider if the journal can deliver the research point of view to the right audience and contribute to building knowledge in the literature (Md Khudzari, Kurian, Tartakovsky, and Raghavan, 2018). 
Table 1.

Summary of Top 10 most productive journals on tourism experience research

\begin{tabular}{|c|c|c|c|c|c|c|c|}
\hline & Journal & $\begin{array}{l}\text { TP } \\
\text { (\%) }\end{array}$ & TC & $\begin{array}{l}\text { CiteScore } \\
2018\end{array}$ & $\begin{array}{l}\text { The most cited } \\
\text { article }\end{array}$ & $\begin{array}{l}\text { Times } \\
\text { cited }\end{array}$ & Publisher \\
\hline 1 & $\begin{array}{l}\text { Tourism } \\
\text { Management }\end{array}$ & $\begin{array}{l}125 \\
(4.7)\end{array}$ & 7,459 & 8.2 & $\begin{array}{l}\text { Value } \\
\text { dimensions, } \\
\text { perceived value, } \\
\text { satisfaction, and } \\
\text { loyalty: An } \\
\text { investigation of } \\
\text { university } \\
\text { students' travel } \\
\text { behaviour }\end{array}$ & 579 & Elsevier \\
\hline 2 & $\begin{array}{l}\text { Annals of } \\
\text { Tourism } \\
\text { Research }\end{array}$ & $\begin{array}{l}117 \\
(4.4)\end{array}$ & 9,827 & 4.55 & $\begin{array}{l}\text { Rethinking } \\
\text { authenticity in } \\
\text { tourism } \\
\text { experience }\end{array}$ & 1,336 & Elsevier \\
\hline 3 & $\begin{array}{l}\text { Journal of } \\
\text { Travel } \\
\text { Research }\end{array}$ & $\begin{array}{l}96 \\
(3.6)\end{array}$ & 5,828 & 7.04 & $\begin{array}{l}\text { Developing the } \\
\text { travel careers } \\
\text { approach to } \\
\text { tourist } \\
\text { motivation. }\end{array}$ & 433 & SAGE \\
\hline 4 & $\begin{array}{l}\text { Journal of } \\
\text { Travel and } \\
\text { Tourism } \\
\text { Marketing }\end{array}$ & $\begin{array}{l}65 \\
(2.5)\end{array}$ & 1,542 & 3.53 & $\begin{array}{l}\text { The effect of risk } \\
\text { perceptions on } \\
\text { intentions to } \\
\text { travel in the } \\
\text { aftermath of } \\
\text { September 11, } \\
2001\end{array}$ & 132 & Taylor \& Francis \\
\hline 5 & $\begin{array}{l}\text { Current } \\
\text { Issues in } \\
\text { Tourism }\end{array}$ & $\begin{array}{l}58 \\
(2.2)\end{array}$ & 975 & 3.91 & $\begin{array}{l}\text { The relationship } \\
\text { between the } \\
\text { 'push' and 'pull' } \\
\text { factors of a } \\
\text { tourist } \\
\text { destination: The } \\
\text { role of } \\
\text { nationality - An } \\
\text { analytical } \\
\text { qualitative } \\
\text { research } \\
\text { approach }\end{array}$ & 140 & Taylor \& Francis \\
\hline 6 & $\begin{array}{l}\text { Journal of } \\
\text { Sustainable } \\
\text { Tourism }\end{array}$ & $\begin{array}{l}45 \\
(1.7)\end{array}$ & 1,450 & 4.06 & $\begin{array}{l}\text { Food, place and } \\
\text { authenticity: } \\
\text { local food and } \\
\text { the sustainable }\end{array}$ & 369 & Taylor \& Francis \\
\hline
\end{tabular}




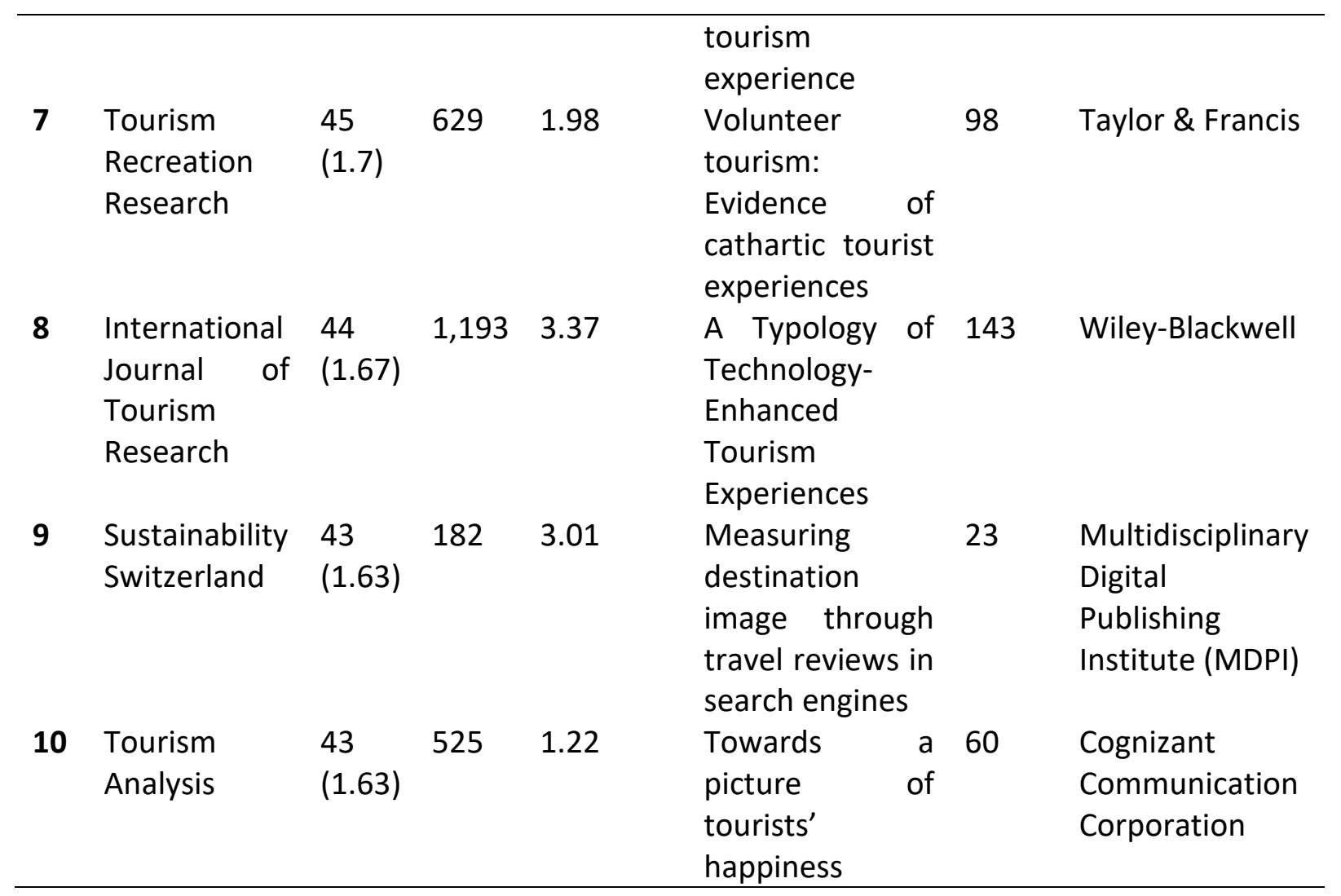

** TP - Total Publication, TC - Total Citation

Top Country Publications and International Affiliations

Figure 4 illustrates the top 15 most productive countries in publications of TE study worldwide. Notably, $21 \%$ of TE publications derived from the US, indicating that the US is a significant player in the TE research domain. Australia followed this with 347 publications (13\%) in the TE field publications. Based on Table 2, among the top 15 countries, only two countries had more than $50 \%$ for their SCP; the US (78.5\%) and Australia (53.8\%). Both the US and Australia displayed significant internal countries publications. The countries did not rely on co-publication with other countries to generate research work on TE. 


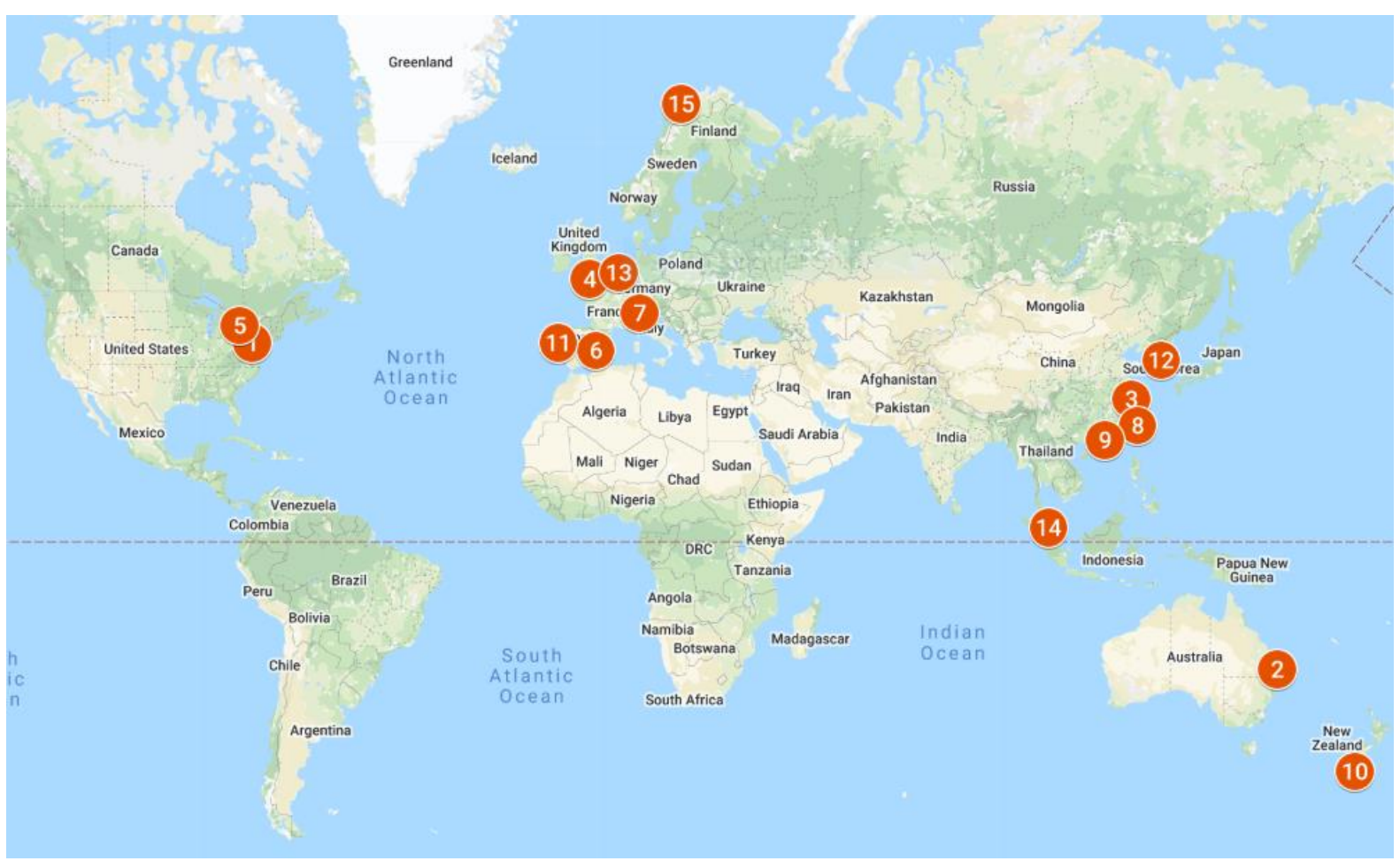

Figure 3 Top 15 most productive countries in tourism experience publications

In comparison, Hong Kong was the country with the least SCP at $7.1 \%$, in which 43 out of 68 publications were linked to multiple affiliations from 12 countries. It showed that international collaboration advantages were not limited to the expanding network or exchange of knowledge and sharing expertise, but also an influential ranking up strategy. The Hong Kong Polytechnic University recorded the highest total publication institution (TPi) with 68 publications, followed by Griffith University of Australia (54), Pennsylvania State University of the US (33), and Bournemouth University of the UK (30).

Hence, researchers should be encouraged to engage in international collaborations and provide continued funding. It is a vital role of research institutions to publish articles. The QS World University Ranking is a recognised annual publication released by Quacquarelli Symonds (QS). The institution rank is based on six indicators: academic reputation, employer reputation, citations per faculty, faculty or student ratio, international faculty ratio, and international student ratio. Based on the World University Rankings 2019, the seven universities listed in the top 50 universities for Hospitality and Leisure Management subject area (QS Top Universities, 2020) were: Hong Kong Polytechnic University (4th), Bournemouth University (10th), Taylor's University Malaysia (14th), Griffith University (20th), Pennsylvania State University (23rd), and University of Waterloo (32nd). It demonstrated that the TE field had received attention at the top-ranked universities in the Hospitality and Leisure Management area. 


\section{Table 2}

Top 15 most productive countries and institutions in tourism experience publications

\begin{tabular}{lllllll}
\hline Rank & Country & TP & SCP (\%) & $\begin{array}{l}\text { Most Productive } \\
\text { Institutions }\end{array}$ & Academic & TPi \\
\hline 1 & USA & 561 & 78.5 & Pennsylvania State University & 33 \\
2 & Australia & 347 & 53.8 & Griffith University & 54 \\
3 & China & 293 & 37.5 & Zhejiang University & 20 \\
4 & UK & 289 & 46.0 & Bournemouth University & 30 \\
5 & Canada & 116 & 14.0 & University of Waterloo & 26 \\
6 & Spain & 112 & 18.1 & University of Valencia & 14 \\
7 & Italy & 108 & 15.3 & University of Bergamo & 6 \\
8 & Taiwan & 96 & 15.3 & Shih Chien University & 8 \\
9 & Hong Kong & 92 & 7.1 & Hong Kong Polytechnic University & 68 \\
10 & New Zealand & 85 & 10.5 & University of Otago & 26 \\
11 & Portugal & 83 & 13.5 & University of Aveiro & 19 \\
12 & South Korea & 77 & 8.5 & Kyung Hee University & 14 \\
13 & Netherlands & 72 & 9.2 & Breda University of Applied Sciences & 14 \\
14 & Malaysia & 68 & 12.6 & Taylor's University Malaysia & 16 \\
15 & Norway & 54 & 7.8 & UiT The Arctic University of Norway & 22 \\
\hline$* *$ TP Total Publication, SCP - Single Country Publication, TPi - Total Publication Institutions
\end{tabular}

Figure 5 illustrates the distributions of the bibliometric map for countries coauthorship. Under VOSviewer, the closer the two countries are located, the stronger their coauthorship relationship is. The analysis showed (see Figure 5) that the most significant number of countries per country derived from Europe (34 countries), followed by Asia (30), US (19), Africa (16), and Oceania (4); summing to 103 countries. Co-authorship analysis mapping showed that the US was the most affiliated country, linked to 43 countries with 255 co-authorship frequencies. They were followed by Australia (38 links, 141 co-authorships), UK (36 links, 115 co-authorships), China (24 links, 164 co-authorships), and Italy (24 links, 61 coauthorships). Besides, 2/3 of the listed countries had international collaborative publications with fewer than 10 countries. 


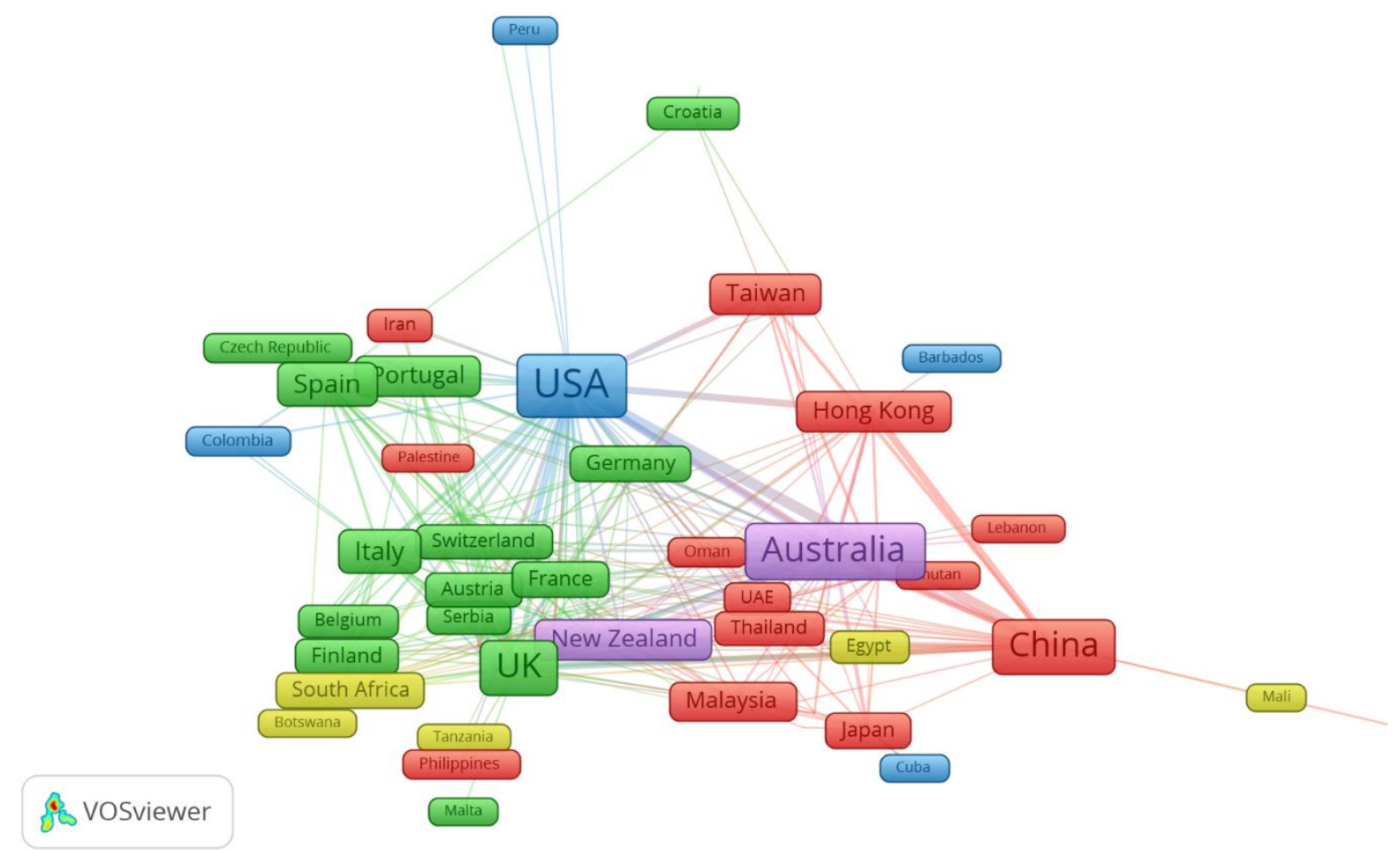

Figure 4. A bibliometric map created based on co-authorship with network visualisation mode. The following URL can access Figure 5 in VOSviewer: http://bit.ly/2uVucWG

Additionally, Tunisia, Kenya, Ethiopia, Argentina, Liberia, Guam, Namibia, Morocco, the Bahamas, and Fiji had no connection with another country. However, with the advancement of communication modes and international travel ease, successful international collaboration becomes possible. Academics find it easier than ever to communicate with foreign experts, thus enabling the sharing of scientific ideas more straightforward. A collaborative approach is essential in sharing knowledge and making equipment, facilities, and laboratories accessible to other researchers.

Leading Authors

This study listed the top 15 authors in TE publication (see Table 2) deriving from seven countries. Australia ranked first with four authors, followed by three authors from the US, while Portugal, Hong Kong, and China each had two authors. Meanwhile, one author represented Canada and Israel each. Despite the absence of a specific rule for order of authors, in routine practice, the last position belongs to supervisors or industry practitioners. The author's affiliation suggests that empirical tourism research derived from a wide range of business, management, environmental, and computer science domains. 
Table 3

List of the Top 15 most prolific authors in the tourism experience research area

\begin{tabular}{|c|c|c|c|c|c|c|c|c|c|}
\hline & Author & $\begin{array}{l}\text { Scopus } \\
\text { author ID }\end{array}$ & $\begin{array}{l}\text { Year of } \\
1^{\text {st }} \\
\text { publicati } \\
\text { on }\end{array}$ & TP & $\begin{array}{l}\text { Autho } \\
\text { r Rank }\end{array}$ & $\begin{array}{l}h- \\
\text { inde } \\
x\end{array}$ & TC & $\begin{array}{l}\text { Current } \\
\text { affiliation }\end{array}$ & $\begin{array}{l}\text { Countr } \\
y\end{array}$ \\
\hline 1 & $\begin{array}{l}\text { Pearce, } \\
\text { Philip L. }\end{array}$ & $\begin{array}{l}710321271 \\
2\end{array}$ & 1983 & 14 & $1^{\text {st }}$ & 38 & $\begin{array}{l}1,23 \\
8\end{array}$ & $\begin{array}{l}\text { James } \\
\text { Cook } \\
\text { University } \\
\text {, Australia, } \\
\text { Townsville }\end{array}$ & $\begin{array}{l}\text { Austral } \\
\text { ia }\end{array}$ \\
\hline 2 & $\begin{array}{l}\text { Coghlan, } \\
\text { Alexand } \\
\text { ra }\end{array}$ & $\begin{array}{l}356122963 \\
00\end{array}$ & 2008 & 13 & $1^{\text {st }}$ & 18 & 200 & $\begin{array}{l}\text { Griffith } \\
\text { University } \\
\text {, Brisbane }\end{array}$ & $\begin{array}{l}\text { Austral } \\
\text { ia }\end{array}$ \\
\hline 3 & $\begin{array}{l}\text { Poria, } \\
\text { Yaniv }\end{array}$ & $\begin{array}{l}660300227 \\
8\end{array}$ & 2004 & 13 & $1^{\text {st }}$ & 20 & 406 & $\begin{array}{l}\text { Ben- } \\
\text { Gurion } \\
\text { University } \\
\text { of the } \\
\text { Negev, } \\
\text { Beersheb } \\
\text { a }\end{array}$ & Israel \\
\hline 4 & $\begin{array}{l}\text { Kastenh } \\
\text { olz, } \\
\text { Elisabet } \\
\text { h }\end{array}$ & $\begin{array}{l}650829810 \\
0\end{array}$ & 2005 & 12 & $2^{\text {nd }}$ & 19 & 186 & $\begin{array}{l}\text { University } \\
\text { of Aveiro, } \\
\text { Aveiro }\end{array}$ & $\begin{array}{l}\text { Portug } \\
\text { al }\end{array}$ \\
\hline 5 & $\begin{array}{l}\text { Lehto, } \\
\text { Xinran } \\
\text { You }\end{array}$ & $\begin{array}{l}650715758 \\
3\end{array}$ & 2008 & 10 & $2^{\text {nd }}$ & 30 & 100 & $\begin{array}{l}\text { Purdue } \\
\text { University } \\
\text { West } \\
\text { Lafayette }\end{array}$ & USA \\
\hline 6 & $\begin{array}{l}\text { Wall, } \\
\text { Geoffrey }\end{array}$ & $\begin{array}{l}356098189 \\
00\end{array}$ & 1997 & 10 & $2^{\text {nd }}$ & 37 & 249 & $\begin{array}{l}\text { University } \\
\text { of } \\
\text { Waterloo, } \\
\text { Waterloo }\end{array}$ & Canada \\
\hline 7 & $\begin{array}{l}\text { Berdych } \\
\text { evsky, } \\
\text { Liza }\end{array}$ & $\begin{array}{l}553179074 \\
00\end{array}$ & 2013 & 9 & $1^{\text {st }}$ & 11 & 156 & $\begin{array}{l}\text { University } \\
\text { of Illinois } \\
\text { at Urbana- } \\
\text { Champaig } \\
\text { n, Urbana }\end{array}$ & USA \\
\hline 8 & $\begin{array}{l}\text { Fesenm } \\
\text { aier, } \\
\text { Daniel R. }\end{array}$ & $\begin{array}{l}670162216 \\
0\end{array}$ & 1994 & 9 & $2^{\text {nd }}$ & 42 & $\begin{array}{l}106 \\
7\end{array}$ & $\begin{array}{l}\text { Florida } \\
\text { Internatio } \\
\text { nal } \\
\text { University } \\
\text {, Miami }\end{array}$ & USA \\
\hline 9 & $\begin{array}{l}\text { Laing, } \\
\text { Jennifer } \\
\text { H. }\end{array}$ & $\begin{array}{l}700603512 \\
5\end{array}$ & 2005 & 9 & $1^{\text {st }}$ & 16 & 213 & $\begin{array}{l}\text { La Trobe } \\
\text { University }\end{array}$ & $\begin{array}{l}\text { Austral } \\
\text { ia }\end{array}$ \\
\hline
\end{tabular}




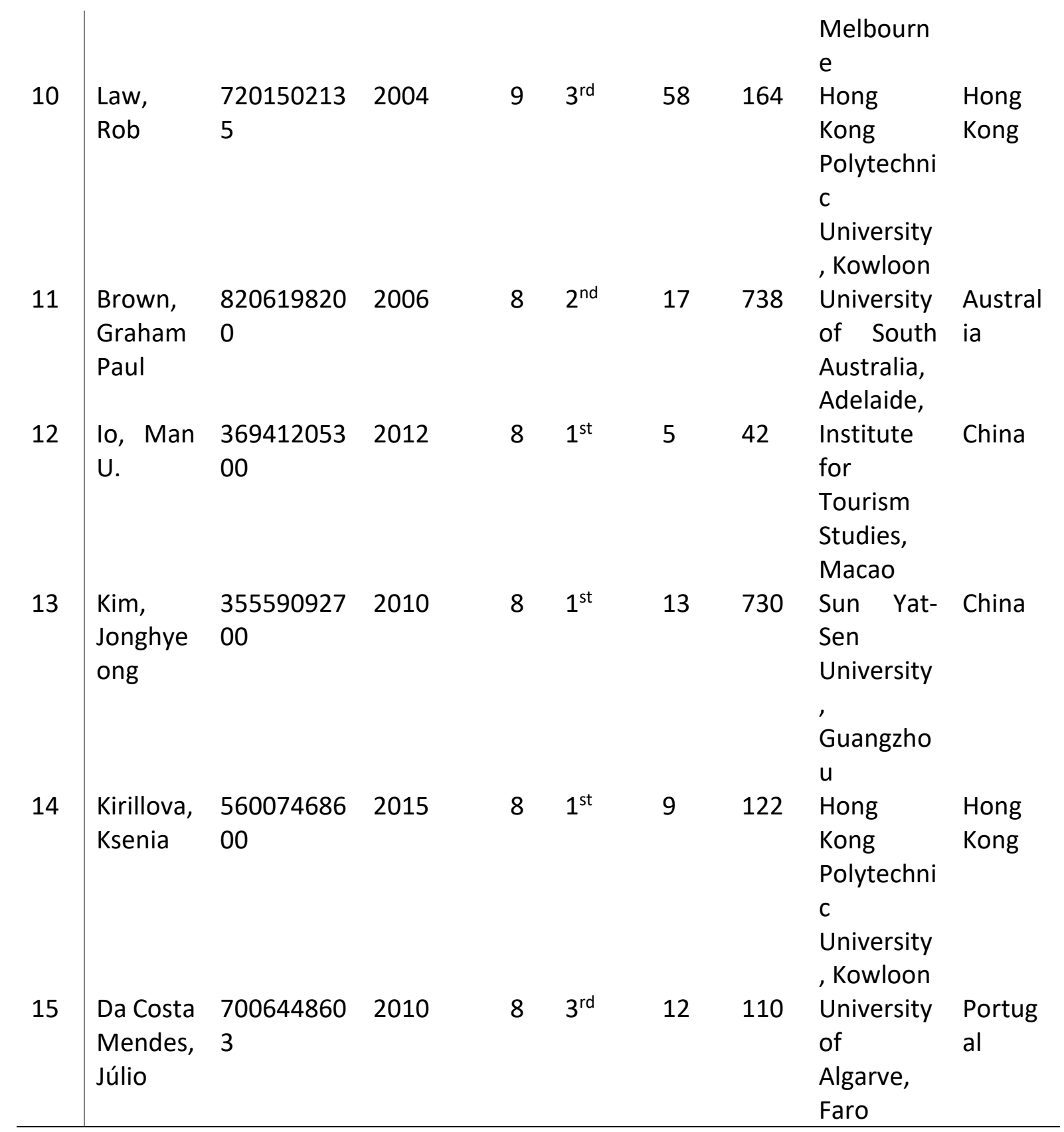

** TP - Total Publication, TC - Total Citation

Based on the analysis, the top prolific author in TE research area is Philip L. Pearce from James Cook University Townsville, Australia, with 14 articles, an h-index of 38, and total citations of 1,238. His earliest articles were published in 1983. The author wrote the most cited articles with Lee Uk-II. The study examines the relationship between travel motivation and travel experience (Pearce and Lee, 2005). This article was cited 475 times in the Scopus database. The next prolific author is Alexandra Coghlan, associated with Griffith University, Brisbane, Australia, with 13 publications and an h-index of 18. Poria, Yaniv, affiliated with BenGurion University of the Negev, Beersheba Israel, followed 13 publications and 406 total citations. Despite being ranked 13th among the top 15 prolific authors, Kim, Jonghyeong from Sun Yat-Sen University in Guangzhou, China, had the second highest citations at 730, 8 publications, and an h-index of 13. 
Authors' Keywords

This section discusses the type of keywords that researchers frequently used. In total, 6,714 keywords were recorded, among which 1,314 were used twice, 670 thrice, and 426 were used four times. Researchers reassigned synonymous single words and congeneric phrases and set the threshold for an occurrence to 5, resulting in 305 keywords in the VOSviewer map.

\section{Terminology and Concept}

The rectangle in Figure 6 represents the keyword frequencies - higher frequency of keywords generates a larger circle. The thickness of the line is related to how closely the two keywords are connected - thinner line indicates tighter connection between the two keywords. Figure 6 shows that 'tourism' was the most frequently used keyword, with 229 occurrences and 144 links to other keywords. Some general terms used in the TE research domain are 'tourist experience' (156 occurrences, 121 links), 'tourism experience' (86 occurrences, 83 links), 'experience' ( 85 occurrences, 94 links), 'authenticity' ( 74 occurrences, 72 links), 'satisfaction' (74 occurrences, 65 links), 'motivation' (61 occurrences, 55 links), 'travel experience' (56 occurrences, 58 links), 'travel' (56 occurrences, 43 links), 'emotion' (43 occurrences, 45 links), and 'destination image' (41 occurrences, 44 links).

It was interesting to see how the keyword 'tourist experience' was linked to different categories of tourism, such as cultural tourism, rural tourism, sustainable tourism, dark tourism, creative tourism, film tourism, wildlife tourism, and smart tourism. For example, creative tourism emerged as a new form of tourism with significant contribution in differentiating, diversifying, and changing the TE (Richard, 2009). Different destinations used different terms for creative tourism, such as 'Creative Life' in Taiwan, 'Creative Paris', 'Creative Tourism New Zealand', 'DIY Santa Fe' in New Mexico, 'Creative Tourism Australia', and 'Creative Tourism Austria'.

This analysis identified several keywords for the research methodology, including netnography (25 occurrences, 40 links), content analysis (21 occurrences, 30 links), usergenerated content (12 occurrences, 14 links), auto-ethnography (10 occurrences, 13 links), grounded theory (7 occurrences, 9 links), importance-performance analysis (7 occurrences, 9 links), sentiment analysis ( 7 occurrences, 9 links), and thematic analysis (6 occurrences, 9 links). According to Kozinets (2015), netnography presents a new approach in conducting ethical and rigorous ethnographic research. It integrates work on archival and online communication, observation and engagement, new forms of network and digital data collection, representation, and analysis of outcomes. It is a qualitative research method specifically designed to study online cultures and communities. 


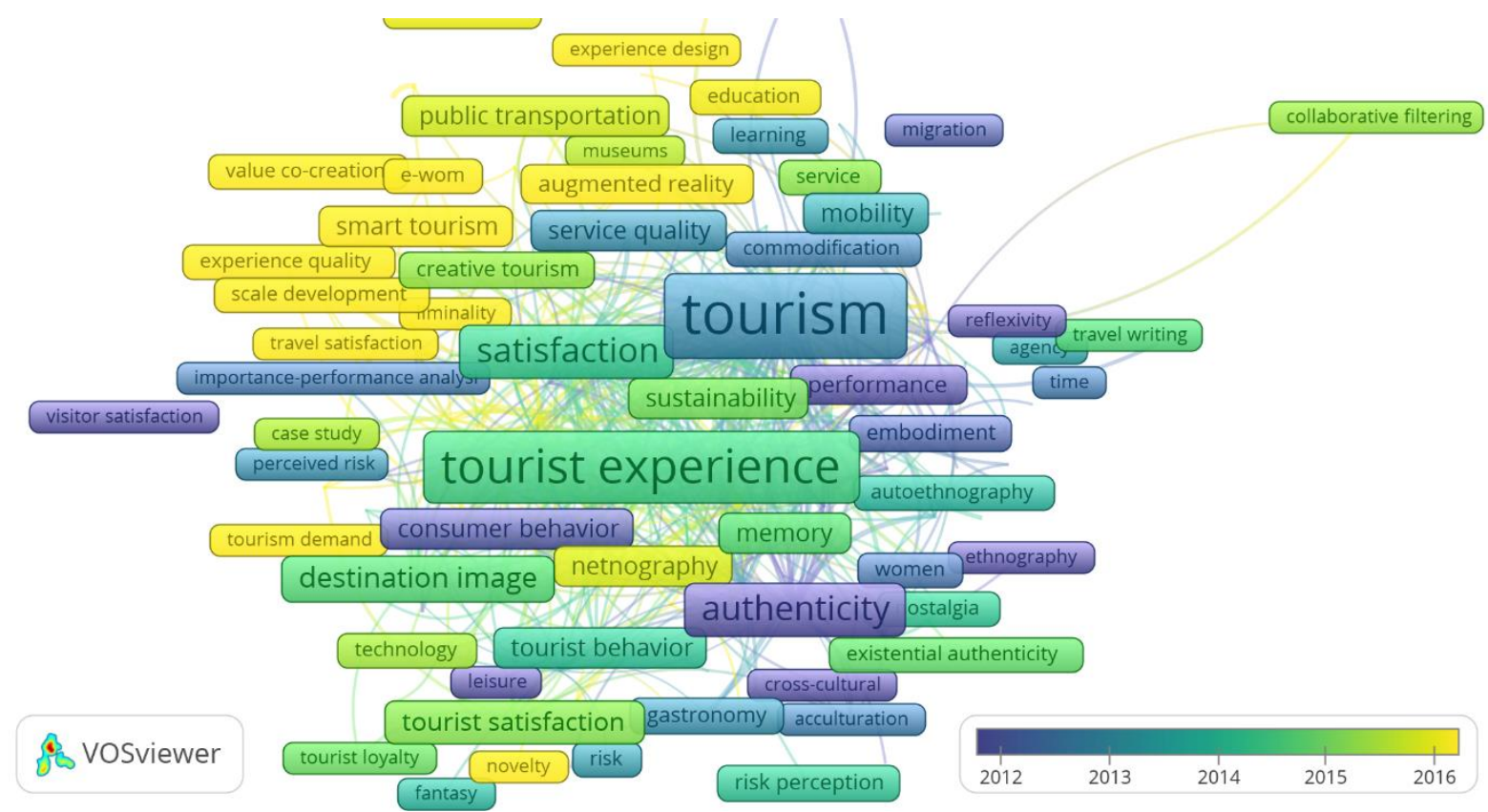

Figure 6. A bibliometric map created based on authors keyword co-occurrence with overlay visualisation mode. Minimum occurrences of a keyword set to five. The following URL can access Figure 6 in VOSviewer: http://bit.ly/2VDS4ZQ

\section{Topic of Interest}

Academics and practitioners have formed a strong interest in TE research domain. Several studies revealed the value of attracting tourists or repeat tourists while increasing global competitiveness among tourist destinations (Cavagnaro, Staffieri, and Postma, 2018; Chen and Rahman, 2018; Ritchie, Tung, and Ritchie, 2010; Vada, Prentice, and Hsiao, 2019). Figure 2 displays the rising number of scientific publications. Keywords, such as 'tourism experience', 'tourist experience', and 'experience' appeared 327 times with 298 links to other keywords from 2013 to 2015.

The TE research segment is not based on objects or events, but personal feelings influenced by activities. According to Quilan Cutler and Carmichael (2010), the two realms in TE are influential and personal realms. From the psychological aspect, the evaluation of experiences is affected by elements of the personal realm. This can be seen from keywords, such as 'satisfaction' (74 occurrences, 65 links), 'motivation' (61 occurrences, 55 links), 'emotion' (43 occurrences, 45 links), 'memory' (25 occurrences, 42 links), 'loyalty' (20 occurrences, 28 links), 'perception' (19 occurrences, 26 links), and 'expectation' (7 occurrences, 11 links).

Generally, 'satisfaction' is discussed as an overall result of the TE. Service organisations use customer satisfaction data to assess service/product quality and to increase customer retention (Chi and $\mathrm{Qu}, 2008$ ). However, satisfaction alone is inadequate to make a tourist revisit a destination (Chen and Rahman, 2018). Hultman, Skarmeas, Oghazi, and Beheshti (2015) failed to identify the direct impact of satisfaction on revisit intentions when examining tourist loyalty. Kim (2018) observed that the direct impact of satisfaction is comparatively lower than that of memorable TE and destination image. 
Another topic of interest in this study is the link between TE and tourism categories. This is noticed from the author's keyword results. The tourism categories that have appeared are 'culture tourism' and 'rural tourism' (34 co-occurrences); 'sustainable tourism' and 'nature-based tourism' (30 occurrences); 'dark tourism' and 'voluntourism' (28 occurrences), 'wine tourism' and 'heritage tourism' (24 occurrences); 'ecotourism' and 'wildlife tourism' (23 occurrences); as well as 'nature-based tourism' and 'smart tourism' (21 occurrences).

The co-occurrences studies revealed the continuous appearance of various experiences in different tourism categories, including indigenous tourism, food tourism, smart tourism, urban tourism, adventure tourism, cruise tourism, and film tourism. With an average publication year of 2017.5 (see Table S2, Appendix B), the result showed that 'smart tourism' (21 occurrences, 20 link strength) was the latest category in TE research domain.

According to Hunter, Chung, Gretzel, and Koo (2015), smart tourism is a social phenomenon that combines information and communication technology (ICT) with TE. Smart tourism refers to tourist destinations as smart destinations or smart cities. The key aspect of smart destinations is integrating ICT into physical infrastructure (Gretzel, Sigala, Xiang, and Koo, 2015). Smart tourism is a significant phase in the development of ICT in tourism. Thus, the tourism industry has changed again. The way TE created, exchanged, consumed, and shared appeared to be radically different (Hunter, Chung, Gretzel, and Koo, 2015).

The link strength of two keywords can also analyse research interest in certain areas. For example, 'memory' had 63 total link strength (connected to 63 keywords), namely 'tourism experience', 'memorable tourism experience', 'behavioural intention', 'emotion', 'experience economy', and 'memorable experience'. In the present tourism research and practice, the value of promoting memorable experiences for tourists has been gaining attention (Manthiou et al., 2016).

Kim and Ritchie (2014) suggested that tourists are more likely to gain a memorable experience on a trip when they can immerse themselves in the tourism activities within the destination. Thus, scholars should strive to better understand the various types of TE and understand how tourists interpret and appreciate tourism experiences (Ritchie, Tung, and Ritchie, 2010). This progression may lead to creating a systematic taxonomy of experiential types and the benefits of which will apply to both managers and academics.

'Authenticity' occurred to be an interesting keyword in TE research domain with 74 occurrences, 72 links, and 133 link strengths. Wang (1999) noted that authentic tourist encounters are not based on objects, but rather on personal feelings towards tourist activity. Authenticity is synonymous with the acquisition of an authentic self or state of being. As shown in Figure 6, the keyword 'authenticity' is linked to several keywords. The keywords are 'heritage tourism', 'acculturation', 'interpretation', 'cultural tourism', 'commodification', and 'destination image'. In tourism, 'authenticity' faces a challenge with global information and communications technology growth. Advancing technology is likely to boost the TE, such as the emergence of human-robot relationship in the encounter of TE (Tung and Law, 2017). 


\section{Limitations of Study}

To date, no review in bibliometric analysis has focused on the TE research domain. Several obstacles were noted to describe the findings discussed above. First, the review of cooccurrence includes all publications in the Scopus database. It may not be extensive since it dismisses other academic data sources, such as WoS and Google Scholar. Hence, in future study may consider other databases such as WoS or Google Scholar. Besides, when performing bibliometric research, the results obtained by using multiple databases would be rather comprehensive. Next, the limited keywords search for titles and abstracts ('tourism experience', 'travel experience', and 'tourist experience') may fail to cover all TE research aspects available on Scopus. Researchers may not use similar terms in their study, but use other terms including 'visitor experience' and 'traveller experience'. Thus, future study of bibliometric data should include other keywords, other databases, and various methodologies for analysis (e.g., inductive content analysis).

\section{Conclusion}

This analysis presents an overview of scientific research revolving around TE based on 2,638 articles retrieved from Scopus database. TE publications have been experiencing an upward trend since the past 15 years, which is projected to grow further. Both Australia and the US are among the top countries with strong foreign affiliations consistently reported in the TE research area. It is an opportunity for researchers from other countries to have joint publication with researchers from countries with a fine international alliance. Besides, the study offers important insights into TE research which highlights the past and current research topic and guides researchers in these emerging areas. Furthermore, the study shows the availability of the resources, barriers, and gaps in both the literature and practical related to TE research.

Therefore, it is disputable that further study on this subject is required to broaden the awareness of $T E$, in which the tourist destination should enhance the quality of its hospitality and service. Destination management organisations can employ TE research as a managerial tool to assess their business efficiency and design appropriate strategies to improve tourist satisfaction and behavioural intention. Future research should focus more on individual's subjective evaluation of events related to their TE. It allowed destination marketers to access tourist individual behaviour and personality that may influence tourist choice and decision process. Another factor that may affect TE's future is artificial intelligence and virtual reality in smart tourism and advanced ICT development.

\section{References}

Arnold, H. (1966). Cholera in present time. Travel experiences of a health-officer in Iran. Der Offentliche Gesundheitsdienst, 28(6), 236-240.

Benckendorff, P., \& Zehrer, A. (2013). A network analysis of tourism research. Annals of Tourism Research, 43, 121-149.

Buhalis, D., \& Amaranggana, A. (2015). Smart tourism destination enhancing tourism experience through personalisation of services. In Information and communication technologies in tourism 2015 (pp. 377-389). Springer, Cham.

Cavagnaro, E., Staffieri, S., \& Postma, A. (2018). Understanding millennials' tourism experience: values and meaning to travel as a key for identifying target clusters for youth (sustainable) tourism. Journal of Tourism Futures. 
Chen, H., \& Rahman, I. (2018). Cultural tourism: An analysis of engagement, cultural contact, memorable tourism experience and destination loyalty. Tourism Management Perspectives, 26, 153-163.

Ferreras-Fernández, T., García-Peñalvo, F., Merlo-Vega, J. A., \& Martín-Rodero, H. (2016). Providing open access to PhD theses: visibility and citation benefits. Program.

Gretzel, U., Sigala, M., Xiang, Z., \& Koo, C. (2015). Smart tourism: foundations and developments. Electronic Markets, 25(3), 179-188.

Hunter, W. C., Chung, N., Gretzel, U., \& Koo, C. (2015). Constructivist research in smart tourism. Asia Pacific Journal of Information Systems, 25(1), 105-120.

Kim, J. H., \& Ritchie, J. B. (2014). Cross-cultural validation of a memorable tourism experience scale (MTES). Journal of Travel Research, 53(3), 323-335.

Kozinets, R.V. (2015). Netnography: Redefined. 2nd Ed. Sage Publications, Thousand Oaks, CA.

Manthiou, A., Kang, J., Chiang, L., \& Tang, L. (2016). Investigating the effect of memorable experience: An extended model of script theory. Journal of Travel \& Tourism Marketing, 33(3), 362-379.

Md Khudzari, J., Kurian, J., Tartakovsky, B., \& Raghavan, G. V. (2018). Bibliometric analysis of global research trend on microbial fuel cells using Scopus database. Biochemical Engineering Journal, 136, 51-60.

Moro, S., Rita, P., Esmerado, J., \& Oliveira, C. (2019). Unfolding the drivers for sentiments generated by Airbnb Experiences. International Journal of Culture, Tourism and Hospitality Research, 13 (4), 430-442

Otto, J. E., \& Ritchie, J. R. B. (1996). The service experience in tourism. Tourism Management, $17(3), 165-174$.

Pearce, P. L., \& Lee, U. I. (2005). Developing the travel career approach to tourist motivation. Journal of Travel Research, 43(3), 226-237.

Pine, B. J., \& Gilmore, J. H. (1998). Welcome to the experience economy. Harvard Business Review, 76(4), 97-105.

QS World University Rankings by Subject (2020). Quacquarelli Symonds. https://www.topuniversities.com/university-rankings/university-subjectrankings/2019/hospitality-leisure-management

Richards, G. (2009), "Creative tourism and local development", in Wurzburger, R., Aageson, T., Pattakas, A., and Pratt, S. (eds), Creative Tourism: A Global Conversation: How to Provide Unique Creative Experiences for Travelers Worldwide, Santa Fe: Sunstone, pp. 78-90.

Ritchie, J. R. B., Tung, V. W. S., \& Ritchie, R. J. B. (2011). Tourism experience management research: Emergence, evolution and future directions. International Journal of Comtemporary Hospitality Management, 23(4), 419-438.

Sánchez, A. D., Del Río, M. D. L. C., \& García, J. Á. (2017). Bibliometric analysis of publications on wine tourism in the databases Scopus and WoS. European Research on Management and Business Economics, 23(1), 8-15.

Tung, V. W. S., \& Law, R. (2017). The potential for tourism and hospitality experience research in human-robot interactions. International Journal of Contemporary Hospitality Management, 29(10), 2498-2513.

Vada, S., Prentice, C., \& Hsiao, A. (2019). The influence of tourism experience and well-being on place attachment. Journal of Retailing and Consumer Services, 47, 322-330.

Van Eck, N. J. \& Waltman, L. (2020). Manual for VOSviewer Version 1.6.14. Centre for Science and Technology Studies, Leiden University, The Netherlands. 
Vieira, E. S., \& Gomes, J. A. (2009). A comparison of Scopus and Web of Science for a typical university. Scientometrics, 81(2), 587.

Wagner, A. B. (2010). Open access citation advantage: An annotated bibliography. Issues in Science and Technology Librarianship, 60(2).

Wang, N. (1999). Rethinking authenticity in tourism experience. Annals of Tourism Research, 26(2), 349-370.

Zijlstra, H., \& McCullough, R. (2016). CiteScore: a new metric to help you track journal performance and make decisions. Elsevier, 8. https://www.elsevier.com/editorsupdate/story/journal-metrics/citescore-a-new-metric-to-help-you-choose-the-rightjournal

\section{APPENDIX}

Table A1: The search strategies and query strings used in Scopus database

\begin{tabular}{|c|c|c|c|c|}
\hline Item & Theme & Search for ? & Search string & $\begin{array}{l}\text { Search } \\
\text { results* }\end{array}$ \\
\hline i. & Central & $\begin{array}{l}\text { Tourism } \\
\text { experience or } \\
\text { Travel } \\
\text { experience or } \\
\text { Tourist } \\
\text { experience } \\
\text { research articles }\end{array}$ & $\begin{array}{l}\text { TITLE-ABS ( "tourism experience" } \\
\text { "travel experience" OR } \\
\text { experience" ) AND ( LIMIT-TO ( SRCTYPE, } \\
\text { "j" ) OR LIMIT-TO ( SRCTYPE, "p" ) ) AND } \\
\text { ( LIMIT-TO ( DOCTYPE, "ar") OR LIMIT-TO } \\
\text { ( DOCTYPE, "cp" )) AND ( EXCLUDE ( } \\
\text { PUBYEAR, 2020)) }\end{array}$ & 2,818 \\
\hline ii. & Central & $\begin{array}{l}\text { Review articles in } \\
\text { (i) }\end{array}$ & $\begin{array}{l}\text { TITLE-ABS("tourism experience" OR "travel } \\
\text { experience" OR "tourist experience") AND ( } \\
\text { TITLE ( "recent" OR progress OR review OR } \\
\text { critical OR revisit OR advance OR } \\
\text { development OR highlight OR perspective } \\
\text { OR prospect OR trends OR bibliometric OR } \\
\text { scientometric ) OR ( ABS ( progress OR } \\
\text { review OR bibliometric OR scientometric )) } \\
\text { ) AND ( LIMIT-TO ( SRCTYPE,"j" ) OR LIMIT- } \\
\text { TO ( SRCTYPE,"p" ) ) AND ( LIMIT-TO ( } \\
\text { DOCTYPE,"ar" ) OR LIMIT-TO ( } \\
\text { DOCTYPE,"cp" ) ) AND ( EXCLUDE ( } \\
\text { PUBYEAR,2020)) }\end{array}$ & 413 \\
\hline iii. & Central & $\begin{array}{l}\text { Tourism } \\
\text { experience or } \\
\text { Travel } \\
\text { experience or } \\
\text { Tourist } \\
\text { experience } \\
\text { research articles } \\
\text { without review } \\
\text { articles }\end{array}$ & $\begin{array}{l}\text { TITLE-ABS("tourism experience" OR "travel } \\
\text { experience" OR "tourist experience") AND } \\
\text { NOT EID (insert EID of review articles } \\
\text { here**) ( EXCLUDE ( PUBYEAR,2020) ) AND ( } \\
\text { LIMIT-TO ( DOCTYPE,"ar" ) OR LIMIT-TO ( } \\
\text { DOCTYPE,"cp" ) ) AND ( LIMIT-TO ( } \\
\text { SRCTYPE,"j" ) OR LIMIT-TO ( SRCTYPE,"p" )) }\end{array}$ & 2,638 \\
\hline
\end{tabular}

EID of review articles: 
2-s2.0-85068053357 OR 2-s2.0-85076116776 OR 2-s2.0-85075832225 OR 2-s2.085073238628 OR 2-s2.0-85075821881 OR 2-s2.0-85069046955 OR 2-s2.0-85051973050 OR 2-s2.0-85075688008 OR 2-s2.0-85070253362 OR 2-s2.0-85066629367 OR 2-s2.085063566855 OR 2-s2.0-85067632230 OR 2-s2.0-85059783045 OR 2-s2.0-85063786531 OR 2-s2.0-85044360599 OR 2-s2.0-85067921505 OR 2-s2.0-85055695336 OR 2-s2.085062849197 OR 2-s2.0-85073812587 OR 2-s2.0-85069658718 OR 2-s2.0-85073822257 OR 2 -s2.0-85073775315 OR 2-s2.0-85065032174 OR 2-s2.0-85074410588 OR 2-s2.085065726079 OR 2-s2.0-85078318133 OR 2-s2.0-85078845252 OR 2-s2.0-85067343561 OR 2-s2.0-85064563899 OR 2-s2.0-85048811245 OR 2-s2.0-85073368518 OR 2-s2.085075000025 OR 2-s2.0-85072390618 OR 2-s2.0-85077633308 OR 2-s2.0-85071559131 OR 2-s2.0-85058650709 OR 2-s2.0-85066412670 OR 2-s2.0-85041100555 OR 2-s2.085054742615 OR 2-s2.0-85050008860 OR 2-s2.0-85041039537 OR 2-s2.0-85048891501 OR 2-s2.0-85045985886 OR 2-s2.0-85045003742 OR 2-s2.0-85031803571 OR 2-s2.085044176416 OR 2-s2.0-85057740423 OR 2-s2.0-85065756698 OR 2-s2.0-85072940921 OR 2-s2.0-85044460163 OR 2-s2.0-85038639456 OR 2-s2.0-85038850835 OR 2-s2.085016960736 OR 2-s2.0-85021636386 OR 2-s2.0-85040197980 OR 2-s2.0-85039937951 OR 2-s2.0-85022095292 OR 2-s2.0-85017430198 OR 2-s2.0-85022341819 OR 2-s2.085023624628 OR 2-s2.0-85028696817 OR 2-s2.0-84994246243 OR 2-s2.0-85011076165 OR 2-s2.0-84959122494 OR 2-s2.0-85021177412 OR 2-s2.0-85021909270 OR 2-s2.085049326999 OR 2-s2.0-85051534222 OR 2-s2.0-85032752456 OR 2-s2.0-84953301689 OR 2-s2.0-85045973580 OR 2-s2.0-84954526681 OR 2-s2.0-84975317587 OR 2-s2.084988320439 OR 2-s2.0-85071964251 OR 2-s2.0-84995387916 OR 2-s2.0-84957798463 OR 2-s2.0-84939512312 OR 2-s2.0-85063839288 OR 2-s2.0-84907360107 OR 2-s2.084941170400 OR 2-s2.0-84924794970 OR 2-s2.0-84997795075 OR 2-s2.0-84946913363 OR 2-s2.0-84940547880 OR 2-s2.0-84922565336 OR 2-s2.0-84997785006 OR 2-s2.084928566340 OR 2-s2.0-84940437343 OR 2-s2.0-84938540123 OR 2-s2.0-84940579018 OR 2-s2.0-84948142765 OR 2-s2.0-84976427574 OR 2-s2.0-84976310843 OR 2-s2.084930376710 OR 2-s2.0-84920385261 OR 2-s2.0-84943452391 OR 2-s2.0-84920544353 OR 2-s2.0-84976470835 OR 2-s2.0-84950246616 OR 2-s2.0-84893264224 OR 2-s2.084914708042 OR 2-s2.0-84891665263 OR 2-s2.0-84904979360 OR 2-s2.0-84906277263 OR 2-s2.0-84906668194 OR 2-s2.0-84899644187 OR 2-s2.0-84903204716 OR 2-s2.084937942538 OR 2-s2.0-84880166703 OR 2-s2.0-84885826741 OR 2-s2.0-84878340817 OR 2-s2.0-84884763443 OR 2-s2.0-84884791779 OR 2-s2.0-84881361332 OR 2-s2.084884787128 OR 2-s2.0-84979752443 OR 2-s2.0-84921976491 OR 2-s2.0-84867603283 OR 2-s2.0-84868290435 OR 2-s2.0-84866914576 OR 2-s2.0-84901988040 OR 2-s2.084861601816 OR 2-s2.0-79956224548 OR 2-s2.0-80053256808 OR 2-s2.0-85029096361 OR 2-s2.0-79961109491 OR 2-s2.0-84859835863 OR 2-s2.0-79951968734 OR 2-s2.078049455415 OR 2-s2.0-78650073523 OR 2-s2.0-77956739255 OR 2-s2.0-77950661033 OR 2-s2.0-84979502865 OR 2-s2.0-84861649076 OR 2-s2.0-84997966580 OR 2-s2.085029123355 OR 2-s2.0-78549243787 OR 2-s2.0-71749088237 OR 2-s2.0-84855703836 OR 2-s2.0-70449095037 OR 2-s2.0-67649448789 OR 2-s2.0-61449246517 OR 2-s2.085010496901 OR 2-s2.0-77952481525 OR 2-s2.0-84979917122 OR 2-s2.0-57049122372 OR 2-s2.0-84859977290 OR 2-s2.0-84870634769 OR 2-s2.0-33645086132 OR 2-s2.085024163550 OR 2-s2.0-13644277096 OR 2-s2.0-33644864917 OR 2-s2.0-14544305073 OR 2-s2.0-21444444067 OR 2-s2.0-84979732949 OR 2-s2.0-77954472011 OR 2-s2.0-0141818297 OR 2-s2.0-85050009789 OR 2-s2.0-33745828214 OR 2-s2.0-33646990900 OR 2-s2.00033916731 OR 2-s2.0-84986132624 OR 2-s2.0-0033036070 OR 2-s2.0-0032927714 OR 2- 
INTERNATIONAL JOURNAL OF ACADEMIC RESEARCH IN BUSINESS AND SOCIAL SCIENCES Vol. 12, No. 1, 2022, E-ISSN: 2222-6990 @ 2022 HRMARS

s2.0-0032053290 OR 2-s2.0-0031382956 OR 2-s2.0-58149325185 OR 2-s2.0-84984751003 OR 2-s2.0-33847547939 OR 2-s2.0-0028152696 OR 2-s2.0-84994984295 OR 2-s2.0-0000559038 OR 2-s2.0-0025660131 OR 2-s2.0-84972701300 OR 2-s2.0-84890247871 OR 2-s2.046149140610 OR 2-s2.0-0021643791 OR 2-s2.0-84973187050 OR 2-s2.0-84965585096 